\title{
ANALISIS TUTUPAN VEGETASI MANGROVE DI PULAU MANTEHAGE, TAMAN NASIONAL BUNAKEN, SULAWESI UTARA
}

\author{
(Analysis Of Mangrove Vegetation Closure In Mantehage Island, \\ Bunaken National Park, North Sulawesi)
}

\author{
Jufran Sapsuha ${ }^{{ }^{*}}$, Rignolda Djamaluddin ${ }^{1}$, Calvyn F.A. Sondak ${ }^{1}$, \\ Royke M. Rampengan ${ }^{1}$, Esri T. Opa ${ }^{1}$, Alex D. Kambey ${ }^{2}$ \\ ${ }^{1)}$ Program Studi Ilmu Kelautan Fakultas Perikanan dan IImu Kelautan, \\ Universitas Sam Ratulangi, Manado. \\ ${ }^{2)}$ Program Studi Manajemen Sumber Daya Perairan Fakultas Perikanan dan Ilmu Kelautan, \\ Universitas Sam Ratulangi, Manado. \\ EE-mail: jufransapsuha94@gmail.com
}

\begin{abstract}
Mangrove forest are typical forest growing on along coasts, river mouth saffected by tides. This study was conducted on April to September 2018 in Mantehage Island, Bunaken National Park, North Sulawesi. It was aimed to evaluate vegetation cover change during the period from 1995 to 2017 and to deskrip condition of mangrove vegetation at locations where the vegetation covers were identified to have been change. Image interpretation method and ground checks were applied in the study. RGB composite results of 4731995 Landsat-5 images, RGB 453 of Landsat-7 images in 2005 and RGB 564 of Landsat-8 images in 2017 showed the area of mangrove vegetation cover in 1995, 2005 and 2017 respectively were 1333.95 ha, 1371.53 and 1383.21 ha. There was an increase in the area of mangrove vegetation cover in 1995-2005 covering an area of 37.58 ha and in the years 2005-2017 covering an area of $11.68 \mathrm{ha}$. In total there was an additional vegetation cover change of 49,26 ha for 22 years. Result from ground check indicated that the change in vegetation covers occurred at locations subjected to sedimentation, natural recovery at previous clear-cutting areas and area of artificial plantation. The phenomenan of mangrove diebach was found in the middle part between the two mainlands of Mantehage Island.
\end{abstract}

Keywords : Mangrove, Mantehage Island, Geographic Information System.

Hutan mangrove merupakan tipe hutan yang khas dan tumbuh di sepanjang pantai atau muara sungai yang dipengaruhi oleh pasang surut air laut. Penelitian ini dilakukan dari bulan April-September 2018 di Pulau Mantehage, Taman Nasional Bunaken, Sulawesi Utara dengan tujuan untuk mengevaluasi perubahan tutupan vegetasi mangrove di Pulau Mantehage dengan selang waktu 1995, 2005 dan 2017sertaMendeskripsikan kondisi vegetasi mangrove yang teridentifikasi mengalami perubahan tutupan. Penelitian dilakukan dengan metode interpretasi citra dan survei lapangan (Ground check). Hasil komposit RGB 473 citra Landsat-5 tahun 1995, RGB 453 citra Landsat-7 tahun 2005 dan RGB 564 citra Landsat-8 tahun 2017 menunjukkan luas tutupan vegetasi mangrove pada tahun 1995, 2005 dan 2017 secara berturut-turut adalah $1333,95 \mathrm{ha}, 1371,53$ dan 1383,21 ha. Terjadi penambahan luas tutupan vegetasi mangrove pada tahun 1995-2005 seluas 37,58 ha dan pada tahun $2005-2017$ seluas 11,68 ha, jika dijumlahkan dalam kurun waktu 22 tahun terjadi penambahan luas tutupan vegetasi mangrove sebesar 49,26 ha. Hasil Ground Check di lapangan menunjukkan penambahan luas tutupan vegetasi mangrove terjadi pada lahan yang mengalami sedimentasi, lahan terbuka bekas penebangan yang mengalami pemulihan kembali dan pada lokasi tertentu yang ditanami secara artifisial. Fenomena mangrove dieback ditemukan di lokasi bagian tengah antara dua daratan Pulau Mantehage.

Kata kunci: Mangrove, Pulau Mantehage, Sistem Informasi Geografis.

\section{PENDAHULUAN}

Hutan mangrove merupakan ekosistem utama pendukung aktivitas kehidupan di wilayah pantai dan memegang peranan penting dalam menjaga keseimbangan siklus biologis di lingkungannya. Indonesia memiliki sumberdaya hutan mangrove yang sangat 
luas yang tersebar di wilayah pesisir di berbagai provinsi, membuat Indonesia mendapatkan banyak tantangan dalam pengelolaan ekosistem mangrove, khususnya yang berada pada Pulau-pulau kecil (PPK) (Gunarto, 2004).

Indonesia merupakan negara yang memiliki keragaman jenis mangrove tertinggi, seluruhnya tercatat setidaknya 202 jenis mangrove, meliputi 89 jenis pohon, 5 jenis palma, 19 jenis pemanjat, 44 jenis herba tanah, 44 jenis epifit dan 1 jenis paku. Dari 202 jenis mangrove yang telah diketahui, 166 jenis terdapat di Jawa, 157 jenis di Sumatra, 150 jenis di Kalimantan, 142 jenis di Irian Jaya, 135 jenis di Sulawesi, 133 jenis di Maluku, dan 120 jenis di Kepulauan Sunda Kecil (LIPI, 2014). Beberapa jenis mangrove yang dapat dijumpai di pesisir Indonesia adalah bakau (Rhizophora spp), api-api (Avicennia spp), bogem (Sonneratia spp), tancang (Bruguiera spp), nyirih (Xylocarpus spp), tengar (Ceriops spp), dan buta-buta (Excoecaria spp) (Talib, 2008). Di Pulau Mantehage ditemukan 11 jenis mangrove yaitu: $A$. officinalis, $B$. gymnorrhiza, $B$. parviflora, Ceriops tagal, E. agallocha, Lumitzera littorea, $R$. apiculata, $R$. mucronata, Scyphiphora hydrophylla, $S$. alba dan $X$. moluccensis (Putro et al., 2013).

Mangrove di Taman Nasional Bunaken (TNB) merupakan sumberdaya yang bernilai penting selain terumbu karang dan ekosistem pantai lainnya. Dilaporkan dalam studi awal bahwa mangrove terluas di TNB terdapat di Pulau Mantehage dengan luasan sekitar 1.200 ha (Davie et al., 1996). Struktur komunitas vegetasi mangrove di Pulau Mantehage tergolong berbeda dan tidak biasa karena keanekaragamannya yang tinggi dan usia tegakan diperkirakan telah tua dan mengalami gangguan (dieback)' (Djamaluddin, 2004). Kondisi tersebut menurut Djamaluddin (2018), berkaitan erat dengan faktor geomorfik, geofisik dan biologik yang berlaku di tempat tersebut. Hingga awal tahun 2000, tegakan mangrove di Pulau Mantehage dimanfaatkan oleh masyarakat untuk dijadikan kayu bakar (konsumsi sendiri atau dijual ke Manado dan Nain), bahan baku konstruksi rumah dan perahu, patok 'sero' (sejenis perangkap ikan yang dipasang permanen), dan belakangan dipergunakan untuk budidaya rumput laut (patok dan tempat penjemuran). Skala eksploitasi vegetasi mangrove yang terjadi di tempat ini berdampak terhadap dinamika generasi dan perkembangan komunitas vegetasi mangrove serta perubahan fisik lahan berupa abrasi (Djamaluddin, 2004).

Keberadaan Vegetasi mangrove di Pulau Mantehage merupakan salah satu aset yang penting untuk dijaga dan dilestarikan. Hutan mangrove dapat dikembangkan menjadi suatu kawasan yang menguntungkan baik secara ekologis maupun ekonomis. Oleh karena itu perlu dikembangkan strategi pengelolaan sumberdaya tersebut secara berkelanjutan

Penelitian ini bertujuan untuk mengevaluasi perubahan tutupan vegetasi mangrove pada tiga waktu yang berbeda yaitu; 1995, 2005 dan 2017 serta mendeskripsikan kondisi vegetasi mangrove yang teridentifikasi mangalami perubahan tutupan.

\section{METODE PELAKSANAAN}

Secara umum, metode yang digunakan dalam penelitian ini adalah metode interpretasi citra dan survei lapangan (Ground check).Survei lapangan dilakukan untuk memverifikasi hasil interpretasi citra dan juga mendeskripsian kondisi lahan yang teridentifikasi mengalami perubahan tutupan, sedangkan analisis data dilakukan di Laboratorium Geomorfologi Pantai FPIK UNSRAT.

\section{Lokasi Penelitian}

Secara umum penelitian ini dilakukan di Pulau Mantehage, Taman Nasional Bunaken, Sulawesi Utara, yang merupakan kawasan Taman Nasional Bunaken berdasarkan SK MENHUT NO.730/Kpts-11/1991 dan diresmikan oleh Presiden RI pada bulan Desember 1992 (Saragih, 2004). Lokasi penelitian dapat dilihat pada Gambar 1.

\section{Alat dan Bahan Penelitian}

Sejumlah alat dan bahan digunakan selama pelaksanaan penelitian baik saat pengambilan data di lapangan maupun 
analisis data di Laboratorium. Alat dan bahan serta kegunaannya disajikan dalam Tabel 1.

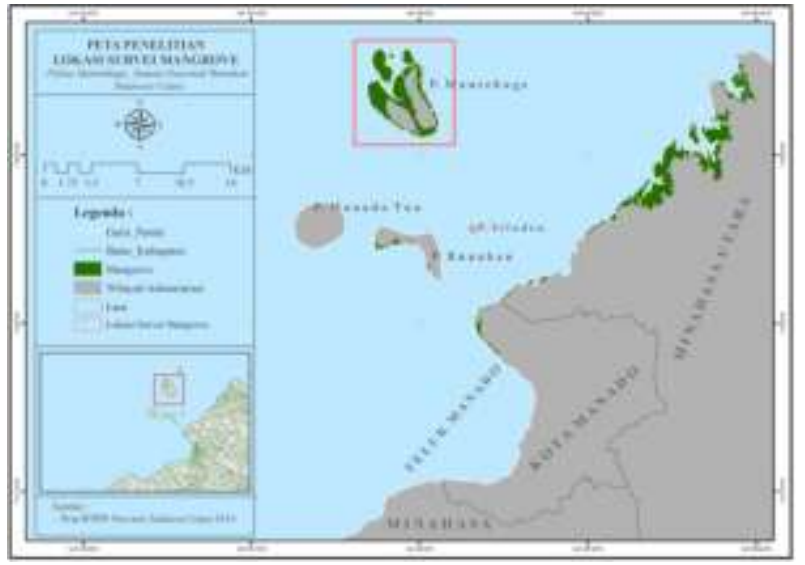

Gambar 1. Peta Lokasi Penelitian

Tabel 1. Alat dan Bahan.

\begin{tabular}{|c|c|c|}
\hline No & Nama Alat dan Bahan & Kegunaan \\
\hline 1 & $\begin{array}{l}\text { Citra Landsat dengan } \\
\text { tahun perekaman 1995, } \\
2005 \text { dan } 2017\end{array}$ & Sebagai data visualisasi \\
\hline 2 & $\begin{array}{l}\text { Peta RTRW Kab. } \\
\text { Minahasa Utara Tahun } \\
2014\end{array}$ & Sebagai peta dasar \\
\hline 3 & $\begin{array}{l}\text { Peta Rupa Bumi } \\
\text { Indonesia Tahun } 1991\end{array}$ & $\begin{array}{l}\text { Mendokumentasikan } \\
\text { kegiatan penelitian }\end{array}$ \\
\hline 4 & $\begin{array}{l}\text { GPS (Global Positioning } \\
\text { System) }\end{array}$ & Menentukan posisi geografis \\
\hline 5 & Kamera & $\begin{array}{l}\text { Dokumentasi situasi yang } \\
\text { berkenaan dengan kegiatan } \\
\text { penelitian }\end{array}$ \\
\hline 6 & $\begin{array}{l}\text { Perangkat Lunak } \\
\text { Komputer (MS. Office } \\
\text { 2010, Global Mapper } 15 \\
\text { dan ArcGIS 10.2.2) }\end{array}$ & $\begin{array}{l}\text { Pengolah kata, data, table } \\
\text { dan peta }\end{array}$ \\
\hline 7 & Alat Tulis Menulis & $\begin{array}{l}\text { Mencatat dan } \\
\text { menggambarkan keadaan di } \\
\text { lapangan }\end{array}$ \\
\hline
\end{tabular}

\section{Prosedur Penelitian}

Penelitian dilakukan dalam beberapa tahapan, diawali dengan pengumpulan data dan informasi dari berbagai sumber, análisis data dan survei lapangan.

\section{Jenis dan Sumber Data}

Data yang digunakan dalam penelitian ini adalah data primer dan data sekunder. Data primer yang digunakan adalah data hasil dokumentasi dan temuan saat survei lapangan. Sedangkan data sekunder adalah data yang didapat dari Situs USGS (webside earthexplorer) dan data yang tersedia dari studi pustaka, maupun publikasi instansi terkait.

Analisis tutupan vegetasi mangrove digunakan data yang terdiri dari beberapa jenis. Peta dasar sebagai bahan visualisasi, menggunakan Peta RBI tahun 1991 dan
Peta RTRW Kabupaten Minahasa Utara tahun 2014.

\section{Penentuan Titik Sampel dan Survei Lapangan}

Sebanyak 16 titik sampel ditentukan dan diamati di lapangan. Titik sampel tersebut ditentukan berdasarkan hasil interpretasi citra yang mengalami perubahan tutupan vegetasi mangrove. Peneliti melakukan pengamatan terhadap kondisi sekeliling titik sampel (BIG, 2014). Metode ini dideskripsikan oleh Djamaluddin (2010) sebagai metode pemeriksaan titik (spot check) yang dapat diterapkan untuk pengamatan struktur vegetasi maupun kondisi umum fisik lahan. Dokumentasi dilakukan terhadap objek yang teramati pada setiap titik sampel.

\section{Pengolahan Data Citra}

\section{a. Pengunduhan Citra}

Citra diperoleh dari Situs USGS (https://earthexplorer.usgs.gov/). Sebelum melakukan pengunduhan citra di Situs USGS, dilakukan proses deliniasi area kasar pengamatan dalam bentuk poligon. Selanjutnya hasil deliniasi dianalisa lanjut untuk menentukan Aol (Area of Interest) sebagai data dalam pembuatan GCP (Ground Control Point). Setelah proses pembuatan GCP selesai, dilanjutkan dengan pengunduhan citra pada situs USGS.

\section{b. Rektifikasi Citra}

Citra yang diunduh pada situs USGS telah teretifikasi, untuk memastikan citra telah teretifikasi menggunakan program ArcGIS10.2 dan Peta RTRW Kabupaten Minahasa Utara tahun 2014 sebagai peta dasar untuk dijadikan acuan dalam menyamakan posisi geografis. Hal ini dilakukan agar dapat mempermudah dalam tahap pengolahan data. Besarnya ambang batas atau threshold nilai RMS Error (Residual Mean Square Error) yang dianggap memenuhi ketelitian planimetrik adalah $\leq 0,5$ kali ukuran piksel citra (Jensen, 1996 dalam Damanik dan Djamaluddin, 2012). 
c. Interpretasi Citra

Hasil berupa tutupan vegetasi mangrove, selanjutnya dianalisis untuk melihat perubahan tutupan vegetasi mangrove yang terjadi dalam kurun waktu 1995, 2005 dan 2017. Proses analisis dilakukan dengan metode interpretasi visual (on-screen digitizing), dengan mengkombinasikan teknik komposit RGB. RGB merupakan singkatan dari Red Green Blue dengan menggabungkan 3 Band yang dapat membedakan wilayah yang akan diteliti. Proses komposit RGB dilakukan dengan menggunakan program ArcGIS10.2. Komposit RGB 473 citra Landsat-5, 453 citra Landsat-7 dan 564 citra Landsat-8 merupakan perpaduan Band yang digunakan untuk melihat wilayah pesisir khususnya mangrove (Green dan Kreuter, 2000). Hasil analisis data interpretasi citra kemudian ditampilkan secara visual berupa peta tutupan vegetasi mangrove.

\section{HASIL DAN PEMBAHASAN}

\section{Deskripsi Umum Lokasi Penelitian}

Pulau Mantehage merupakan salah satu pulau di wilayah Kabupaten Minahasa Utara yang berada di kawasan Taman Nasional Bunaken (TNB). Secara administrasi Pulau Mantehage berada di Kecamatan Wori, Kabupaten Minahasa Utara, Provinsi Sulawesi Utara. Di pulau ini terdapat empat Desa yaitu ; Buhias, Bango, Tangkasi dan Tinongko. Keberadaan mangrove di Pulau Mantehage merupakan sesuatu yang penting untuk dipertahankan karena mangrove memiliki fungsi dan manfaat yang sangat penting bagi kehidupan di Pulau Mantehage dan wilayah sekitarnya.

\section{Peta Tutupan Vegetasi Mangrove}

Berdasarkan hasil interpretasi citra yang dilakukan secara visual (on-screen digitizing), maka didapatkan hasil tutupan vegetasi mangrove di Pulau Mantehage dengan tahun perekaman yang berbeda yaitu: tahun 1995, 2005 dan 2017. Peta tutupan vegetasi mangrove di Pulau Mantehage ditampilkan pada Gambar 2, 3 dan 4.

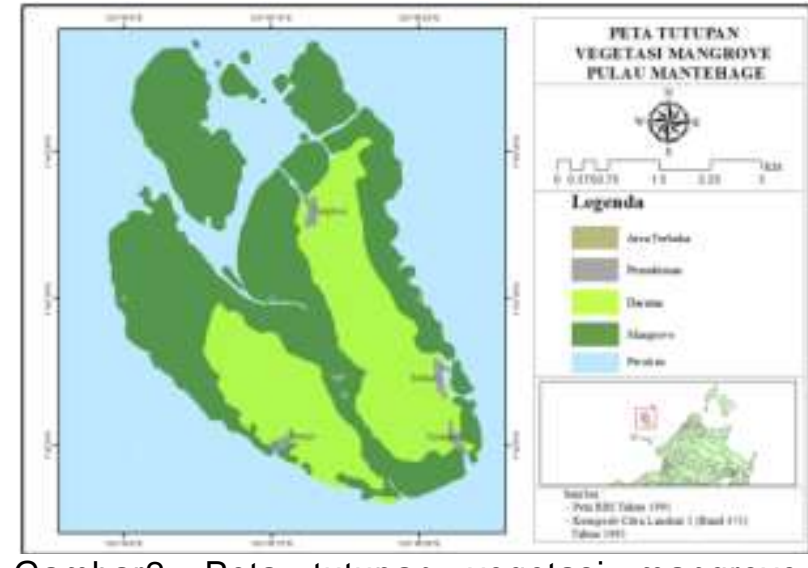

Gambar2. Peta tutupan vegetasi mangrove Pulau Mantehage tahun 1995.

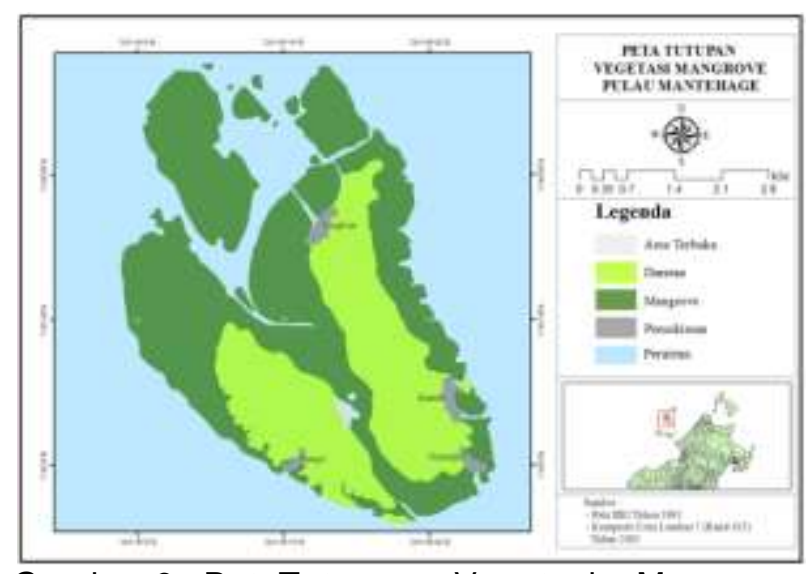

Gambar 3. PetaTutupan Vegetasi Mangrove Pulau Mantehage Tahun 2005.

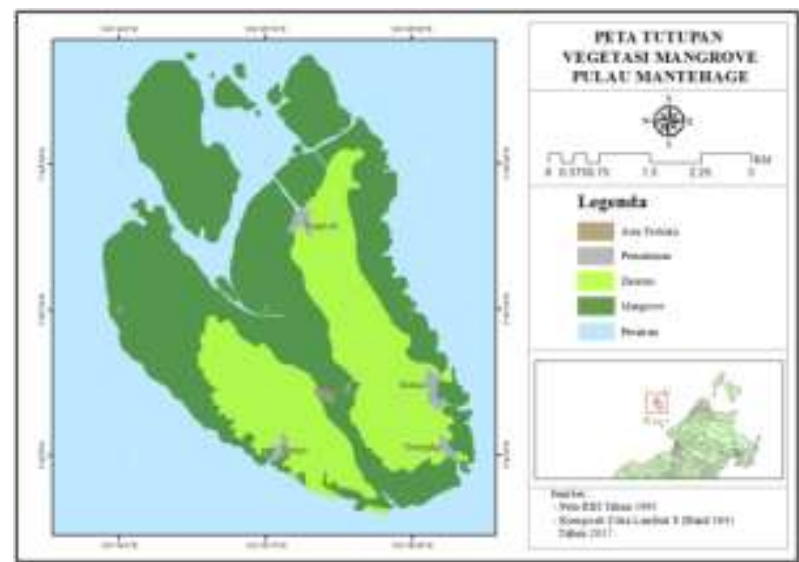

Gambar 4. Peta tutupan vegetasi mangrove Pulau Mantehage tahun 2017.

Gambar 2 merupakan peta tutupan vegetasi mangrove di Pulau Mantehage tahun 1995 didapat dari hasil pengolahan data citra Landsat-5 dengan komposit Band 473 yang direkam pada tanggal 1 Januari 1995. Warna hijau tua merupakan tutupan vegetasi mangrove, warna hijau mudah menunjukkan daratan dan warna abu-abu merupakan pemukiman warga yang menempati Pulau Mantehage. Sedangkan 
Gambar 3 merupakan peta tutupan vegetasi mangrove hasil pengolahan data citra Landsat-7 dengan komposit Band 453 yang direkam pada tanggal 3 Agustus 2005, tutupan vegetasi mangrove di Pulau Mantehage yang berwarna hijau tua semakin bertambah. Hasil interpretasi citra yang dilakukan secara visual (On-screen digitizing)menunjukkan bahwa dalam kurun waktu 10 tahun (1995-2005) vegetasi mangrove di Pulau Mantehage mengalami perubahan tutupan atau vegetasi mangrove semakin meluas.

Gambar 4 merupakan peta tutupan vegetasi mangrove tahun 2017 yang didapat dari hasil pengolahan data citra Landsat-8 dengan komposit Band 564 yang direkam tanggal 31 Desember 2017. Berdasarkan hasil interpretasi citra yang dilakukan secara visual (On-screen digitizing) di Pulau Mantehage tutupan vegetasi mangrove berwarna hijau tua mengalami perubahan luas tutupan atau vegetasi mangrove semakin bertambah dalam kurun waktu 12 tahun (2005-2017). $\mathrm{Hal}$ tersebut ditunjukkan oleh tutupan vegetasi mangrove pada lahan yang sebelumnya terbuka.

\section{Peta Perubahan Luas Tutupan Vegetasi Mangrove}

Perubahan luas tutupan vegetasi dapat dilihat dengan menggunakan metode overlay. Metode overlay merupakan sistem penanganan data dalam perubahan luas vegetasi mangrove dapat dilakukan dengan cara menggabungkan peta tutupan vegetasi mangrove tahun 1995, 2005 dan 2017. Metode tumpang susun peta digunakan untuk mengetahui perubahan luas tutupan vegetasi mangrove di lokasi penelitian. Berdasarkan analisis interpretasi citra yang dilakukan dalam kurun waktu 1995-2017, maka dihasilkan kenampakan perubahan tutupan vegetasi mangrove dalam kurun waktu 22 tahun dapat disajikan pada Gambar 5.

Pada Gambar 5 dapat dilihat perubahan luas tutupan vegetasi mangrove dalam kurun waktu yang berbeda. Warna hijau tua merupakan tutupan vegetasi mangrove tahun 1995. Warna kuning menunjukkan perubahan yang terjadi dalam kurun waktu 10 tahun yaitu dari tahun
1995-2005, perubahan luas vegetasi mangrove berwarna kuning hampir merata di seluruh Pulau Mantehage sedangkan warna merah menunjukkan perubahan luas tutupan vegetasi mangrove dalam kurun waktu 12 dari tahun 2005-2017 tidak merata di seluruh Pulau Mantehage jika dibandingkan dengan tahun 1995-2005. Sementara warna kuning dan merah merupakan perubahan keseluruhan yang terjadi dalam kurun waktu 22 tahun yaitu tahun 1995-2017. Perubahan luas tutupan vegetasi mangrove di Pulau Mantehage dapat dilihat pada Tabel 2.

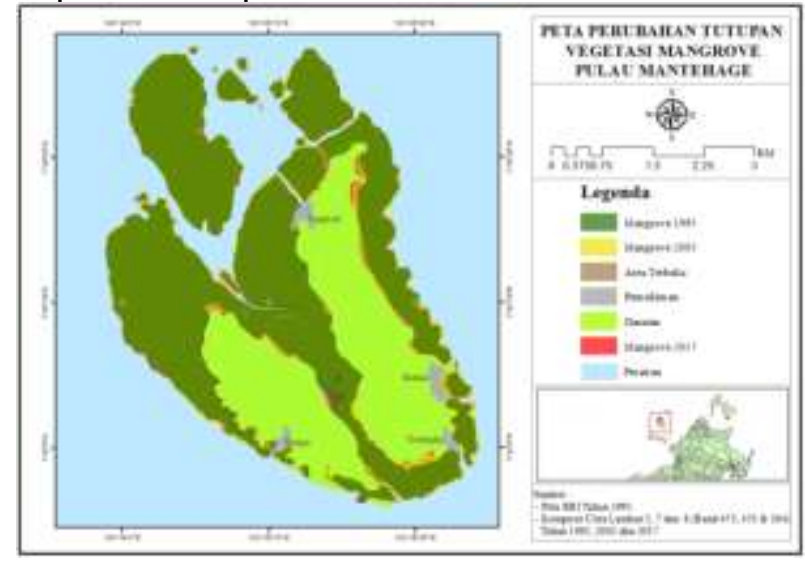

Gambar 5. Peta perubahan luas vegetasi mangrove Pulau Mantehage tahun 1995, 2005 dan 2017.

Tabel 2. Luas dan perubahan tutupan vegetasi mangrove di Pulau Mantehage.

\begin{tabular}{llccc}
\hline \multirow{2}{*}{ No } & \multicolumn{2}{c}{ Luas Mangrove } & \multicolumn{2}{c}{ Perubahan Tutupan Mangrove } \\
\cline { 2 - 5 } & Tahun & $\mathrm{Ha}$ & Tahun & $\mathrm{Ha}$ \\
\hline 1 & 1995 & 1333,95 & $1995-2005$ & 37,58 \\
2 & 2005 & 1371,53 & $2005-2017$ & 11,68 \\
3 & 2017 & 1383,21 & - & - \\
\hline \multicolumn{2}{l}{ Total } & & & 49,26 \\
\hline
\end{tabular}

Tabel 2 menunjukkan bahwa terjadi penambahan luas vegetasi mangrove di Pulau Mantehage. Luas vegetasi mangrove di Pulau ini pada tahun 1995 yaitu 1333,95 ha, tahun 2005 yaitu 1371,53 ha dan pada tahun 2017 yaitu 1383,21 ha. Penambahan luas vegetasi mangrove terbesar terjadi antara tahun 1995-2005 (rentang waktu 10 tahun) dengan luasan sebesar 37,58 ha, sedangkan antara tahun 2005-2017 atau dalam rentang waktu 12 tahun hanya terjadi penambahan luas sebesar 11,68 ha. Dengan demikian, selama kurun waktu 22 tahun (1995-2017) terjadi penambahan luas vegetasi mangrove di Pulau Mantehage sebesar 49,26 ha. 


\section{Deskripsi Kondisi Vegetasi Mangrove dan Perubahan Pada Lahan}

Ekosistem vegetasi mangrove merupakan bagian dari ekosistem wilayah pesisir, sehingga dampak masing-masing ekosistem pesisir akan saling berinteraksi antara satu dengan yang lain. Ekosistem mangrove di Pulau Mantehage teridentifikasi dalam bentuk area terbuka pada lahan mangrove. Berdasarkan hasil interpretasi citra yang dilakukan menunjukkan adanya area terbuka pada lahan mangrove, tepatnya diantara dua daratan di Pulau Mantehage.

Pengamatan lapangan (Ground check) bertujuan untuk mengetahui tingkat ketelitian dari hasil interpretasi citra yang dilakukan secara visual (on-screen digitizing). Observasi dilakukan pada 16 titik pengamatan dimana untuk uji ketelitian klasifikasi terhadap perubahan tutupan vegetasi mangrove yang dilakukan pada 13 titik dan uji ketelitian área terbuka pada lahan mangrove dilakukan pada 3 titik pengamatan. Ground check dilakukan untuk membandingkan hasil interpretasi citra dengan kondisi lapangan yang disesuaikan dengan hasil pengolahan data citra Landsat 8 yang direkam tanggal 31 Desember 2017 dengan obyek yang ditemukan di lapangan. Kondisi pengamatan lapangan ditampilkan pada Gambar 6.

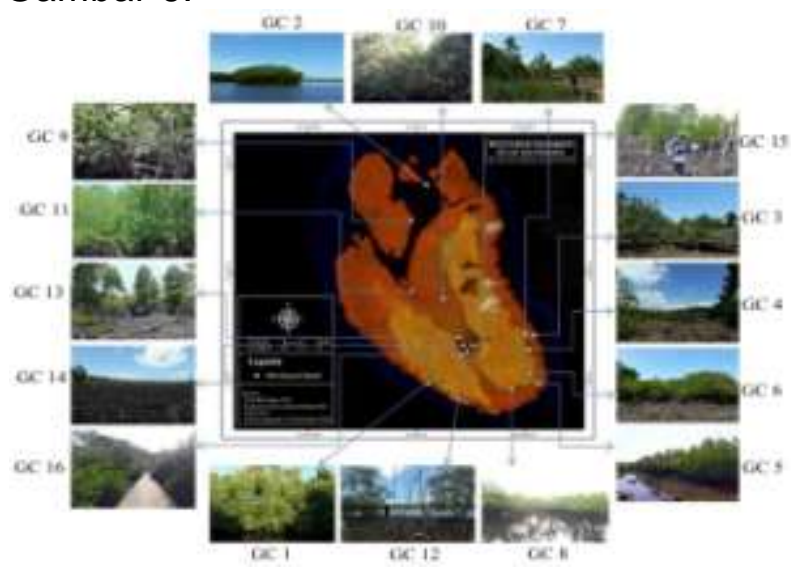

Gambar 6. Kondisi lapangan yang disesuaikan dengan citra Landsat 8 tahun 2017.

Berdasarkan hasil pengecekan di lapangan ditemukan bahwa perubahan luas vegetasi mangrove yang terjadi di Pulau Mantehage berkaitan dengan lahan yang mengalami proses sedimentasi, lahanlahan terbuka bekas penebangan yang telah mengalami pemulihan secara alamiah dan juga adanya penanaman artifisial (campur tangan manusia/penanaman yang dilakukan oleh masyarakat) pada skala tertentu. Pada titik sampel bagian tengah antara dua daratan di Pulau Mantehage ditemukan fenomena mangrove dieback serta ditemukan area terbuka pada lahan mangrove yang mengalami gangguan (mati) secara alamiah. Fenomena ini telah dilaporkan dalam Djamaluddin (2004) sebagai fenomena alami akibat perubahan ekstrim pada lahan yang berkaitan dengan sedimentasi dan gangguan hidrologi.

Di lapangan teridentifikasi bahwa vegetasi mangrove jenis Rhizophora spp. mendominasi lokasi-lokasi yang teridentifikasi mengalami pengangkatan permukaan lahan akibat sedimentasi. Sumber sedimentasi diperkirakan berasal dari aliran sungai pasang-surut yang membelah hutan mangrove di antara kedua daratan di Pulau Mantehage. Pada lokasi yang mengalami pemulihan secara alamiah, teridentifikasi kehadiran tegakan jenis C. tagal di zona dekat daratan dan pertumbuhan vegetatif tegakan jenis $R$. apiculata ke arah laut.

Pertumbuhan vegetatif dapat mengindikasikan bahwa tegakan pernah mengalami penebangan sebelumnya. Interpretasi selanjutnya bahwa pada lokasi ini penebangan tidak lagi berlangsung. Pada sejumlah lokasi penanaman artifisial dilakukan, ditemukan jenis tegakan Rhizophora spp. berukuran kecil (tinggi kanopi kurang dari $1,5 \mathrm{~m}$ ) yang ditanam dengan jarak yang teratur. Pada lahan bagian tengah antara dua daratan di Pulau Mantehage yang mengalami dieback ditemukan kebanyakan tegakan besar jenis Bruguiera cylindrica telah mati dan kering atau roboh. Tegakan muda jenis Lumnitzera racemosa nampak tumbuh pada lokasi ini tetapi sebagian besar tegakan jenis yang sama yang berukuran lebih besar juga mengalami kematian. Substrat permukaan pada lokasi ini relatif dalam dan pada beberapa bagian yang kering nampak pecah-pecah.

Secara umum, dapat digambarkan bahwa pengelolaan mangrove di Pulau Mantehage telah berjalan dengan baik. Proses perkembangan alamiah telah 
berlangsung pada sejumlah lokasi tertentu sehingga terjadi perkembangan komunitas mangrove yang baru, termasuk pemulihan lahan-lahan bekas penebangan. Pada sisi lain, proses alamiah seperti yang teramati di bagian tengah antara dua daratan di Pulau ini juga perlu mendapat perhatian karena terindikasi adanya fenomena mangrove dieback. Ekosistem mangrove Pulau Mantehage tentu saja penting baik secara ekologis dalam mendukung produktivitas perairan sekitar serta untuk perlindungan Pulau Mantehage dari aksiaksi gelombang dan arus dekat pantai yang dapat menyebabkan abrasi.

\section{KESIMPULAN DAN SARAN}

\section{Kesimpulan}

Hasil komposit RGB 473 citra Landsat-5 tahun 1995, RGB 453 citra Landsat-7 tahun 2005 dan RGB 564 citra Landsat-8 tahun 2017 didapatkan luas tutupan vegetasi mangrove pada tahun 1995, 2005 dan 2017, secara berturut-turut adalah 1333,95 ha, 1371,53 dan 1383,21 ha. Berdasarkan hasil interpretasi citra yang dilakukan secara visual (On-screen digitizing) terjadi penambahan jumlah luasan vegetasi mangrove di Pulau Mantehage pada tahun 1995-2005 (kurun waktu 10 tahun) seluas 37,58 ha dan pada tahun 2005-2017 (kurun waktu 12 tahun) seluas 11,68 ha. Bila dijumlahkan secara keseluruhan terjadi penambahan luas vegetasi mangrove sebesar 49,26 ha selama kurun waktu 22 tahun (1995-2017) di Pulau Mantehage.

Hasil pengamatan di lapangan yang dilakukan pada 16 titik pengamatan menunjukkan bahwa penambahan luas vegetasi mangrove di Pulau Mantehage terjadi pada lahan yang mengalami sedimentasi, bekas penebangan yang telah mengalami pemulihan secara alamiah dan pada skala tertentu berkaitan dengan adanya penanaman artificial (Campur tangan manusia/penanaman yang dilakukan oleh masyarakat). Sementara itu, fenomena mangrove dieback dan área terbuka pada lahan mangrove yang telah mengalami gangguan (mati) secara alamiah juga ditemukan di lokasi bagian tengah antara dua daratan di Pulau Mantehage.

\section{Saran}

Berdasarkan penelitian ini maka halhal yang dapat disarankan adalah:

- Diharapkan adanya penelitian serupa yang dilakukan namun dengan resolusi lebih tinggi serta titik lapangan yang lebih banyak

- Disarankan untuk melakukan penelitian lanjutan tentang nilai indeks vegetasi dengan teknik NDVI (Normalised Diference Vegetation Index) untuk mengetahui kondisi vegetasi mangrove yang berada di Pulau Mantehage. Fenomena mangrove dieback di Pulau Mantehage juga perlu mendapat perhatian dan diteliti lebih mendalam.

\section{DAFTAR PUSTAKA}

BIG, 2014. Peraturan Kepala Badan Informasi Geospasial. No. 3 Tahun 2014. Tentang Pedoman Teknis Pengumpulan dan Pengolahan Data Geospasial Mangrove. 115 hal.

Davie, J., Merril, R., Djamaluddin, R. 1996. The Sustainable Use And Conservation Of The Mangrove Ecosystem Of The Bunaken National Park. USAID, Jakarta.

Damanik, R., Djamaluddin, R. 2012. Atlas Mangrove Teluk Tomini. Program SUSCLAM (Sustainable Coastal Livelihoods and Management Program). 91 hal.

Djamaluddin, R. 2004. The Dynamics Of Mangrove Forest In Relation To Dieback And Human Use In Bunaken National Park, North Sulawesi, Indonesia. (Disertasion). University Of Queensland, Brisbane.

Djamaluddin, R. 2010. Survei Kondisi Ekosistem Mangrove di Wilayah Kabupaten Parigi Moutong. SUSCLAM-Teluk Tomini (Sustainable Coastal Livelihoods and Management).

Djamaluddin, R. 2018. The Mangrove Flora And Their Physical Habitat Charcteristics In Bunaken National Park, North Sulawesi, Indonesia.Biodiversitas, 19(4):1303-1312.

Gunarto, 2004. Konservasi Mangrove Sebagai Pendukung Sumber Hayati Perikanan Pantai. Balai Riset Perikanan Budidaya Air Payau. Jurnal Litbang Pertanian, hal 17.

Kementrian Kelautan dan Perikanan, 2012. Jurnal Pulau-pulau Kecil di Indonesia. Direktorat Pendayagunaan Pulau-Pulau Kecil Ditjen Kelautan, Pesisir dan Pulau-pulau Kecil Kementrian Kelautan dan Perikanan. Jakarta.

LIPI, 2014. Kekinian Keanekaragaman Hayati Indonesia. LIPI Pres, anggota Ikapi. Pusat Penelitian Biologi.

Putro, S.E., Tarisin, J.S., Lasut, M.T., Langi, M.A. 2013. Struktur dan Komposisi Vegetasi Mangrove di Pulau Mantehage. Program Studi IImu 
Kehutanan, Jurusan Budidaya Pertanian, Fakultas Pertanian UNSRAT. Manado. $6 \mathrm{Hal}$.

Saragih, C.E.A., 2004. Studi Morfologi Pantai Pulau Bunaken Bagian Tenggara. Rencana Kerja Penelitian Fakultas Perikanan dan IImu Kelautan UNSRAT Manado.
Talib, M.F. 2008. Struktur dan Pola Zonasi (Sebaran) Mangrove Serta Makrozoobenthos Yang Berkoeksistensi di Desa Tanah Merah dan Oebelo Kecil, Kabupaten Kupang, Program Studi IImu dan Teknologi Kelautan. Institut Pertanian Bogor. Skripsi. 87hal. 